\title{
Subjective-existential interpretation of ideas about the educational environment of students in a situation of prolonged academic failure
}

\author{
Yuliya Makarevskaya, ${ }^{1 *}$ Zinaida Ryabikina $^{2}$ and Irina Makarevskaya ${ }^{1}$ \\ ${ }^{1}$ Sochi State University, 354000 Sochi, Russia \\ ${ }^{2}$ Kuban State University, 350000 Krasnodar, Russia
}

\begin{abstract}
The article analyzes the features of ideas about the educational environment of students who have been in a situation of educational failure for a long period of time. Analysis and interpretation of the results are conducted on the basis of a subjective-existential approach to personality. The main position of the given approach assumes the presence of opportunities and basic needs of the person for the demonstration (selffulfillment) of himself in various spaces of being. Blocking these opportunities (objective or subjectively understood) deprives a person of subjective activity. The article poses and remains open the question of personal dispositions of situations of failure. Variants of ideas about the forming environment of underachieving (according to objective parameters) students are viewed. The study defined the relationship between the leading trends of the environment (personality data in representations) and real achievements of the personality in these specific situational conditions. The levelling of activity as an environmental parameter in the representations of underachieving students is shown. Being space is not interpreted by the person as providing an opportunity to be active at low objective indicators of the success of activities implemented in this environment.
\end{abstract}

\section{Introduction}

People are constantly involved in various activities and carry out this or that behavior. The behavior and activity of the subject always have a result, as a consequence of two factors: personal (subjective) and situational (objective).

By objective conditions we mean those phenomena and circumstances which are independent of the will and consciousness of the subject that are necessary for the born of this phenomenon. But they are still insufficient by themselves. Moreover, the origin of this

\footnotetext{
* Corresponding author: yuliya-sochi@mail.ru
} 
event depends on a subjective factor that manifests itself right on the basis of these objective conditions. The subjective factor is the purposeful activity of the subject, aimed at changing, developing or maintaining objective conditions.

The subjective factor of behavior and activity in psychology is understood as dispositional parameters of a person (needs, motives, attitudes, values, ideas, selfidentification), and situational as the external environment, conditions surrounding the individual (other people's behavior, attitudes, assessments, reactions of others, physical conditions etc.).

Most scientific approaches to explaining human behavior admit the role of situational (environmental, social) factors in the development and manifestation of the mental. However, among the various approaches, differences in what importance is attached to situational and what to personal factors in determining the behavior of the subject, are clearly noticeable. Proponents of situational approaches deduce the specificity of behavior from the situation itself. These provisions are confirmed in psychological theories of the situation [1-6 and others]. Approaches that give priority to personal factors take the situation as an impulse to actualize the appropriate disposition, and even in a number of concepts personal impulses considered as factors in the creation of certain social situations [7-9]. Moreover, the subject does not always determine this or that situation, sometimes he simply reacts to it, while simultaneously defining himself in this situation. Therefore, the personality actually creates the social world in which it lives.

That is, we proceed from the premise that the subject acts in accordance with how he evaluates and interprets the surrounding reality. The role of personality dispositions boils down not so much to direct determination of behavior as to participation in the formation of cognitive assessment schemes by which the subject interprets the situation. Further actions are the result of this interpretation.

In addition, there is the subjectivity of the personality, which is not a characteristic that the person possesses or does not possess, every time it is a choice dispositionally made by the person in a particular situation.

Thus the provisions of the psychology of human existence (humanistic and existential psychology) [10-12], the subjective approach [13, 14] were integrated into the modern, already actually established subject-being approach, which assumes a new understanding of the relationship between the individual and the environment of being (Z.I. Ryabikina, L.N. Ozhigova, G.Yu. Fomenko, G.G. Tanasov, etc.) [15-17]. An approach that proposes to understand subjectivity as the ability of a person to be not just encouraged by within or outside, but by the source and cause of his actions in external existential spaces.

And then, when analyzing the external factors that explain the behavior of the personality, the emphasis is placed not so much on the objective parameters of the environment as on the person's assessment and interpretation of the contextual aspects of its behavior, i.e. the subjective reflection of objective conditions and the importance that person attaches to these conditions.

The subject's perception of the objective parameters of the environment is laid down in the concept of social ideas- as a way of interpreting and understanding everyday reality, a certain form of social cognition, involving cognitive activity of individuals and groups [18].

Representation is not a simple cast of the surrounding world, it is a product and a process of active social and psychological recreation of reality, because a social subject is active in cognitive activity, through representations he re-establishes and, as it were, recreates objects, people, events.

Interpretation of a situation as successful or unsuccessful for a person needs justifications.

Firstly, the subject must be included in the situation (in objective conditions, existence space). 
Secondly, the subject, carrying out any activity, receives a result that, to varying degrees, corresponds to his values, his goals and social norms.

Thirdly, the subject forms an assessment scheme, on the basis of which he experiences certain emotions, therefore living this situation as successful or not successful for himself.

In the evaluative scheme, there is inevitably a subjective and objective component. That is, being unsuccessful in inner subjective experiences, a person can objectively appear before others as a successful social subject. Another option is also possible: when the subjective assessment interprets the activity as successful, and the external objective assessment interprets the situation as unsuccessful for the individual.

In various areas of activity, the measurement of success takes place according to similar scenarios, but with significant differences, because each type of activity has its own sphere of social application and, accordingly, its own goals and objectives. In this case, one way or another, success is largely related to public acceptance of either all human activities or individual achievements. It is appropriate to refer to W. James and emphasize that the action "comes back to us in the form of certain further impression - the impression of our action, and thus we get sensory cognition about our behavior and its results", we "read in the eyes of present a flattering or unflattering for us assessment of our behavior" [17, p.3435]. At the school of K. Levin, on the basis of his work and the study of his colleagues, it was concluded that experiences of success and failure occur only inside the zone of subject's capabilities and in activity that is personally significant for the individual [18].

Consequently, on the basis of the subjective-existential approach, it is possible to define the situation of failure as a combination of external circumstances and internal conditions, experiences, qualities and properties that make it impossible for a person to achieve successes of subjectively desired and socially admitted accomplishments in the subject's self-realization. Self-realization is understood as an adequate realization of "oneself."

That is, the traditional opposition of the "external and internal" in the subject-being approach does not manifest itself as hard as in other areas of psychology, but it still leaves the question: can the inner world be independent of the external assessment? [19, 20 and others].

\section{Materials and methods}

Based on this problem, the main research question is posed: if the subject in the existential spaces of his self-realization receives a negative external assessment of his actions for a long period of time, then how does this relate to his ideas about the environment in which he is being implemented? Are there any specifics in these views?

Thus, for the implementation of the study were necessary:

1) data on objective assessments of the results of the activity of the subject;

2) data on the subject's perception of objective environmental parameters (representations).

It is known that objective assessments of the results of the activity are most clearly manifested in the learning environment. Therefore, the sample was formed from students of the university, and for the first parameter, the academic performance of the subjects for the period of continuous training during the 10 semesters ( 5 years) was chosen.

The presented results were obtained using the archival method of obtaining information (analysis of journals of academic performance), methods of expert evaluation and observation.

Indicators of the performance logs for the group of students included in the sample were analyzed: for each student, the average academic grade point for the entire study period as a whole and for each semester separately (for the analysis of performance dynamics) was calculated. 
In comparison with the average group performance indicators, it was noted that some students can be classified as underachieving by the criterion of their average score, which did not exceed (for all 10 semesters) the value of 3.86 points. And although some of them sometimes received a " 4 " mark in the learning process, none of them ever received the highest mark on a standard five-point scale. Therefore, indicators in all semesters (except for the 1st) pass below the average group values of academic achievement.

Additional criteria for differentiation were:

- the number of retakes from unsatisfactory grades in exams and from failures;

- the number of non-appearance both for exams and tests;

- data of expert assessments by teachers of performance of students included in the sample;

- observation data for students included in the sample throughout 2.5 years (5 semesters);

- data of frequent and content analysis of signs of a failure situation (based on a survey using the method of unfinished sentences, $\mathrm{N}=103$ ).

\section{Results}

Thus, on the basis of the data obtained, according to the law of normal distribution, the sample was differentiated between students who are successful and failing according to the criterion of the average academic score.

The average mark of underachieving students was 3.48, and for special subjects of the curriculum, he was even lower - 3.38. Successful students on average received 4.5 points in all subjects and 4.6 in special subjects of the curriculum. That is, specialization disciplines are even more difficult for underperforming students than general education.

According to the frequent content analysis of the signs of failure situation, students received a rating of criteria (in decreasing order of occurrence), presented below.

According to the parameter of academic performance:

1. did not pass exams, cannot pass the session;

2. low academic performance;

3. expelled;

4. does not hold knowledge.

According to the behavior parameter:

1. does not attend classes, skips;

2. does not take an active part in the life of the university. dull, not bright, boring, does not manifest himself;

3. does not prepare for classes, responds poorly at practical classes;

4. he can't pay for his studies, can't independently cope with his own problems.

Only those students who met the above criteria remained in the final sample. That is, data on objective evaluations of the subject's performance were obtained on a representative sample.

Data on the perception (submissions) by the subject of the environment itself was obtained by the method of modeling the educational environment.

To justify the chosen method, you relied on 2 provisions:

1) entrance examinations to a higher educational institution approximately "equalize" the students' chances according to the criteria of their cognitive abilities and the level of general awareness in the process of achieving success in educational activities;

2) the environment of existence provides subjects with equal opportunities for selfrealization.

In this aspect, which methodologically fits into the subject-being approach, the theory of possibilities of $\mathrm{J}$. Gibson is proposed, which suggests moving away from the 
interpretation of the one-sided influence of either the environment on the person or the person on the environment. The category of opportunity by J. Gibson emphasizes the subjectivity (active beginning) of a person mastering his living environment. Opportunity thus acts as a bridge between the subject and the space of being (environment) [21]. A person can take from the existential environment everything that is necessary for him to carry out vital functions that correspond to the nature of this subject. And if he does not take, then does he know himself poorly? And does not see the possibilities of the environment for himself? Or does he lack subjectivity?

Opportunity (according to Gibson) can determine both the properties of the environment and the properties of the subject itself. The more fully a person sees and uses the capabilities of the environment (manifesting his subjectivity), the more successful is its free and active self-development, self-realization in the spaces of being. These findings are related to the concept of $\mathrm{W}$. James discussed above.

In the aspect of this study, it is especially important to emphasize once again that the assessments of another person are important for the subjective perception by a person of a situation as successful or unsuccessful. A person for another person also acts as an element of the environment, influencing him through his relationships and actions.

Based on the results of answers to diagnostic questions, a corresponding vector is constructed in the coordinate system, which allows typologizing and characterizing this educational environment in the subjects' ideas as creative, career, dogmatic, or serene.

Thus, we obtained a sample differentiated among people who were highly successful by external objective criteria in a given existential space, in this activity, as well as people who were admitted as objectively unsuccessful, who had been in a situation of educational failure for a long period of time (at least 2.5 years) and data on the content of the subjects' ideas about the environment in which they study, in which they have the potential for selfrealization.

Diagnosis of ideas about the educational environment showed the following distribution (Table 1).

Table 1. Diagnosis of ideas about the educational environment

\begin{tabular}{|c|c|c|}
\hline $\begin{array}{c}\text { Type of educational } \\
\text { environment }\end{array}$ & $\begin{array}{c}\text { Successful } \\
(\%)\end{array}$ & $\begin{array}{c}\text { Unsuccessful } \\
(\%)\end{array}$ \\
\hline Creative & 9.9 & 13.6 \\
\hline Career & 71.6 & 59.1 \\
\hline Dogmatic & 12.3 & 22.7 \\
\hline Serene & 2.5 & 4.5 \\
\hline
\end{tabular}

The sample size was 103 people, of whom 81 were successful students and 22 people were long time unsuccessful.

Considering the data in percentage expression, it can be said that underperforming students expect freedom $(18.1 \%$ and $12.4 \%)$ from the educational environment more than successful students, at the same time, underperforming students perceive it more as forming passivity (27.2\% and $14.8 \%)$.

That is, the environment gives unsuccessful students the freedom of choice, autonomy, independence of opinions and actions, but at the same time they do not see the opportunity to show initiative, desire for something, perseverance in the desire, fighting for their interests and defending them. 


\section{Conclusion}

The Chi-square test showed that, as a whole, there are no statistically significant differences in the perception of the educational environment between successful and unsuccessful students.

Only, among successful and unsuccessful girls, there are significant differences in the perception of the educational environment as a career $\left(\mathrm{X}^{2} \mathrm{emp} .=3.94, \mathrm{p} \leq 0.05\right)$. Namely, girls who are successful in education are much more likely than unsuccessful to present the educational environment as giving them opportunities for cold calculation, perseverance, networking, advertising their virtues, and quest for a career.

Among unsuccessful students, such ideas about the educational environment are much less. It is possible that this environment is not the existential space where they see their selffulfillment as the most probable, therefore they do not make a choice in favor of activity, self-manifestation, or self-realization.

\section{References}

1. M. Argyle, A. Furnham, J. Craharn, Social Situations (Cambridge, 1981)

2. L. Ross, R. Nisbett, Man and the situation. Prospects for Social Psychology (Moscow, 1999)

3. E. Magnusson., B. Ekehammar, 8, 331-39 (1973)

4. C.F. Graumann, A. Metraux, G.Schneider Ansätze des Sinnverstehens (München, 1995)

5. H. Thomae, Psychologische Biographie Als Synthese Idiographischer und nomothetischer Forschung (Berlin; Heidelberg; New York: Springer-Verlag, 1987).

6. L.F. Burlachuk, E.Yu. Korzhova, Psychology of Life Situations (Moscow, 1998)

7. A.G.Asmolov, Psychology of Personality. Principles of general psychological analysis (Moscow, 1990)

8. O.I. Brodchenko, The influence of psychological characteristics of personality on the perception of social situations (Moscow, 1996)

9. D.A. Leontiev, Personal in personality: personal potential as the basis of selfdetermination (Moscow, 2002)

10. A.H. Maslow, The farther reaches of human nature (New York, 1971).

11. W.Frankl, Man in search of meaning (Moscow, 1990)

12. D.A.Leontiev, Psychological Journal, 21, 15-25 (2000)

13. Subject, personality and psychology of human existence (Moscow, 2005)

14. The subjective approach in psychology (Moscow, 2009)

15. V.V. Znakov, Z.I. Ryabikina, The psychology of human being (Moscow, 2017)

16. T.P. Emelyanova, Psychology Issues. 6, 28-47 (2001)

17. W. James, Psychology in conversations with the teacher (St. Petersburg, 2001)

18. K. Lewin, Field theory in social science (New York, 1951)

19. Z.I. Ryabikina, Scientific materials of the V Congress of the All-Russian Public Organization "Russian Psychological Society". 3 (2012)

20. T.V. Gavrilenko, Z.I. Scientific journal KubSAU. 134, (2017)

21. J.J. Gibson, The Ecological Approach to Visual Perception (Boston, 1979) 